\title{
$\beta$-Catenin Overexpression in the Mouse Brain Phenocopies Lithium-Sensitive Behaviors
}

\author{
Todd D Gould', Haim Einat ',2, Kelley C O’Donnell', Alyssa M Picchini' ${ }^{1,3}$, Robert J Schloesser' and \\ Husseini K Manji*,I \\ 'Laboratory of Molecular Pathophysiology, National Institute of Mental Health, National Institutes of Health, Bethesda, MD, USA
}

\begin{abstract}
Lithium inhibits glycogen synthase kinase-3 (GSK-3) at therapeutic concentrations; however, it is unclear if this inhibition and its downstream effects on specific signaling pathways are relevant to the treatment of bipolar disorder and depression. One of the targets of GSK-3 is the transcription factor $\beta$-catenin. Normally active GSK-3 phosphorylates $\beta$-catenin, leading to its degradation. Inhibition of GSK3 therefore increases $\beta$-catenin. We have utilized transgenic mice to investigate the behavioral consequences of CNS $\beta$-catenin overexpression. Transgenic mice overexpressing $\beta$-catenin demonstrated behavioral changes similar to those observed following the administration of lithium, including decreased immobility time in the forced swim test (FST). Further, we show that although acute administration of lithium and overexpression of the $\beta$-catenin transgene inhibits $d$-amphetamine-induced hyperlocomotion, neither lithium nor the $\beta$-catenin transgene prevents $d$-amphetamine-induced sensitization, as measured by locomotor activity. Both lithiumtreated and $\beta$-catenin mice had an elevated response to $d$-amphetamine following multiple administrations of the stimulant, though the difference in absolute locomotion was maintained throughout the sensitization time-course. Neither acute lithium nor $\beta$-catenin overexpression had an effect on $d$-amphetamine-induced stereotyped behavior. The results of this study, in which $\beta$-catenin transgenic mice exhibited behaviors identical to those observed in lithium-treated mice, are consistent with the hypothesis that the behavioral effects of lithium in these models are mediated through its direct inhibition of GSK-3 and the consequent increase in $\beta$-catenin. By associating the behavioral effects of lithium with $\beta$-catenin levels, these data suggest that increasing $\beta$-catenin might be a novel therapeutic strategy for mood disorders.

Neuropsychopharmacology (2007) 32, 2173-2183; doi:I0.1038/sj.npp. I 30I338; published online I4 February 2007
\end{abstract}

Keywords: hyperactivity; Wnt pathway; mania; depression; animal model; lithium

\section{INTRODUCTION}

More than $1 \%$ of the world population suffers from severe bipolar disorder, and up to $15 \%$ suffers from severe depression. Lithium exerts both antimanic and antidepressant actions (collectively referred to as mood stabilization) when used clinically. Although lithium has been in clinical use worldwide for three decades, the therapeutic mechanism of action of this monovalent cation remains unknown. It is anticipated that understanding the therapeutic target of

*Correspondence: Dr HK Manji, Laboratory of Molecular Pathophysiology, National Institute of Mental Health, National Institutes of Health, 35 Convent Drive, Bldg 35, Rm IC-912, Bethesda, MD 2089237। I, USA, Tel: + I 30| 402 9802, Fax: + | 3014800123 ,

E-mail: manjih@mail.nih.gov

${ }^{2}$ Current address: Department of Pharmacy Practice and Pharmaceutical Sciences, College of Pharmacy, University of Minnesota Duluth, Duluth, MN, USA.

${ }^{3}$ Current address: Department of Pharmacology, Columbia College of Physicians and Surgeons, New York, NY, USA.

Received 24 February 2006; revised 20 November 2006; accepted 18 December 2006 lithium will lead to an improved understanding of the pathophysiology of these disorders, and for the ability to treat patients with more specific and efficacious medications. Studies that attempt to discern lithium's therapeutic target are critical for the development of lithium-mimetic compounds with fewer side effects.

At therapeutic concentrations, lithium inhibits a small number of enzymes via competition with magnesium. In mammals, this group includes at least four related phosphomonoesterases (the best known of which is inositol monophosphatase), the metabolic enzyme phosphoglucomutase, and the multifunctional enzyme glycogen synthase kinase-3 (GSK-3) (Gould et al, 2004c; Klein and Melton, 1996; Naccarato et al, 1974; Ray et al, 1978; Stambolic et al, 1996; York et al, 1995). The 1996 discovery that lithium inhibits GSK-3 raised the question of whether that inhibition might be relevant to the therapeutic consequences of lithium administration (Klein and Melton, 1996; Stambolic et al, 1996); however, the specific relation of this inhibition to the mood stabilizing properties of lithium is still unclear. One approach, which might provide evidence beyond the biochemical effects of lithium, is to understand 
the behavioral effects of lithium in model organisms. Emerging evidence suggests that many of the behavioral effects of lithium may be caused by inhibition of GSK-3 (Beaulieu et al, 2004; Gould et al, 2004b; Kaidanovich-Beilin et al, 2004; O'Brien et al, 2004). However, GSK-3 has a number of cellular functions, and understanding the GSK-3 target most relevant to lithium's behavioral effects is therefore the next logical step in characterizing the relevant effects of lithium on rodent behavior.

A primary pathway regulated by GSK-3 is the Wnt signaling pathway. Activation of the Wnt signaling pathway leads to an increase in $\beta$-catenin, which acts as a nuclear transcription factor. The constitutively active enzyme GSK3 is a critical negative regulator of this pathway, in which it phosphorylates $\beta$-catenin, resulting in its ubiqitin-dependent degradation (Aberle et al, 1997; Orford et al, 1997). When GSK-3 is inhibited within a protein complex in the Wnt signaling pathway, or by an inhibitor such as lithium, GSK-3 does not phosphorylate $\beta$-catenin. The unphosphorylated $\beta$-catenin is therefore not degraded, a consequence that leads to increased cellular levels of $\beta$-catenin (Behrens et al, 1998; Peifer et al, 1994; Yost et al, 1996). At therapeutically relevant concentrations (serum concentrations between 0.5 and $1.2 \mathrm{mM}$ ), lithium increases $\beta$-catenin and Wnt-mediated gene expression in the brains of rodents, suggesting relevance to the clinical effects of the drug (De Ferrari et al, 2003; Gould et al, 2004a, 2006; O'Brien et al, 2004). Specifically, four weeks of daily i.p. injections of lithium chloride increased $\beta$-catenin in the rat brain (De Ferrari et al, 2003). O'Brien and colleagues reported that 7 days of administration of lithium chloride in rodent chow increased $\beta$-catenin levels in the mouse hypothalamus, as well as Wnt-driven gene expression in reporter mice (O'Brien et al, 2004). Both 9 and 30 days of administration of lithium carbonate in rodent chow increased $\beta$-catenin levels in the frontal cortex of rats (Gould et al, 2004a, 2006).

To determine the role of $\beta$-catenin in regulating the behavioral effects of lithium we utilized transgenic mice that overexpress a constitutively active form of $\beta$-catenin in the adult CNS (Kratz et al, 2002). The behaviors these mice exhibited were compared to the behavioral response to lithium exhibited in wild-type mice. We found that lithiumsensitive behaviors are phenocopied by overexpression of $\beta$-catenin in the mouse brain; notably, both lithium and $\beta$ catenin overexpression have mood stabilizer-like effects in standard models of mania ( $d$-amphetamine hyperlocomotion) and depression (FST).

\section{MATERIALS AND METHODS}

\section{Animals}

Mut-2 transgenic mice contain the S37F mutant $\beta$-catenin cDNA with a $3^{\prime}$ FLAG epitope sequence under control of the murine PrP promoter element (Kratz et al, 2002). Phosphorylation of serine 37 by GSK-3 makes $\beta$-catenin a target for ubiquitin-dependent degradation, and the alteration of this site to an alanine results in constitutively high levels of $\beta$-catenin (Furlong and Morin, 2000). DNA was extracted from tail clips by proteinase $\mathrm{K}$ digestion followed by ethanol precipitation. The transgene was detected by PCR amplification of a $200 \mathrm{bp}$ product using a forward primer located in the $\beta$-catenin cDNA sequence $\left(\beta\right.$ cat $3 \mathrm{pb}: 5^{\prime}$ TCGTTCTTTTCACTCTGGTGGAT- $3^{\prime}$ ) and a reverse primer in the PrP promoter (PrP-S: $5^{\prime}$-GTGGATACCCCCTCCCC CAGCCTAGACC- $3^{\prime}$ ). A $750 \mathrm{bp}$ control band was produced by amplification from the endogenous PrP gene using PrP-S and the reverse primer (PrP-AS: $5^{\prime}$-CCTCTTTGTGAC TATGTGGACTGATGTCGG-3') (Kratz et al, 2002). Transgene expression from the $\operatorname{PrP}$ promoter is generally extremely low during embryonic development, with highlevel postnatal expression largely restricted to neurons and glia of the CNS (Borchelt et al, 1996). Mice were received and maintained on a C57BL/6J background (The Jackson Laboratories, Bar Harbor, ME), and all pups were the product of a hemizygous male and WT female mating and of at least seven backcrosses. All experiments were performed with 8-12 week, randomly selected male littermates derived from multiple litters. Mice were housed 2-4 per cage in an animal room with constant temperature $\left(22 \pm 1^{\circ} \mathrm{C}\right)$ and $12 \mathrm{~h}$ light/dark cycle (lights on/off at $0600 \mathrm{~h} /$ $1800 \mathrm{~h}$ ), with free access to food and water. All experimental procedures were approved by the National Institute of Mental Health Animal Care and Use Committee, and were conducted in full accordance with the Guide for the Care and Use of Laboratory Animals (Institute of Laboratory Animal Resources (US), 1996). For experiments with mice from outside vendors, mice were transported to our facility, and experimentation started no less than 1 week later, to allow for appropriate acclimatization time. Experiments were performed in the light phase of the light/dark cycle under dimmed lighting.

\section{Baseline Behavioral Studies}

Mice were tested in a variety of behavioral tasks to determine normal sensory function, including vision, hearing, strength, and balance (Crawley, 2000). For the open-field test, mice were placed in the center of a large elevated Plexiglas open field $(120 \times 120 \mathrm{~cm})$ and their behavior was recorded for $45 \mathrm{~min}$ by the Ethovision videotracking system (Noldus; Leesburg, VA). The Ethovision system follows the center of the body of the mouse and records its position according to the location of this point. For the calculation of center time, the center of the open field was defined as $40 \times 40 \mathrm{~cm}$. The black-white box measured $43 \times 25 \times 30 \mathrm{~cm}$ with the black portion being $1 / 3$ of the total size. Mice were placed in the larger, lighted compartment of a two-compartment chamber with an open door between the compartments. The number of transitions between the two chambers and time spent in each were automatically recorded with a video tracking system over a single 5-min test session. An accelerating rotarod (Accuscan Instruments, Inc.) was used with a setting of 4-40 rpm over a time period of $5 \mathrm{~min}$ in the forward direction (Crawley, 2000). On the first day, mice were initially placed on the rotating drum until they did not fall for a period of $30 \mathrm{~s}$. Mice were tested in four trials during day 1 , followed by three trials on days 2 and 3. There was a minimum of 2 min between trials on each day. The Morris water maze measured $160 \mathrm{~cm}$ in diameter. Water was maintained at $23^{\circ} \mathrm{C}$. Briefly, four trials per day were performed for 16 days. The first 2 days were visible platform trials, each $2 \mathrm{~min}$ in duration. The remaining 14 days were hidden platform 
trials also $2 \mathrm{~min}$ in duration. These four daily trials were averaged for daily performance. After training, mice were tested in a 1-min probe trial with the platform removed. Data was acquired and analyzed with HVS Image 20-20 plus tracking system (Hampton, UK).

\section{Forced Swim Test}

For the FST, mice were placed in a cylinder of water between 23 and $25^{\circ} \mathrm{C}$. Mice were videotaped during a 6-min session, which was later analyzed for activity during the final $4 \mathrm{~min}$. At the end of the trial session, mice were taken out of the water, dried with a paper towel and placed back in their home cages. Restraint stress involved $30 \mathrm{~min}$ of restraint per day in a flexible plastic cone, over a period of 7 days. At the end of restraint sessions, mice were inspected for any signs of physical harm and either immediately returned to their home cage or tested in the FST paradigm. In the acute lithium experiments, mice were weighed and then received $100 \mathrm{mg} / \mathrm{kg}$ lithium chloride, followed by testing $30 \mathrm{~min}$ later. For the long-term treatment experiments, at 8 weeks of age, mice were randomly selected to receive either control or lithium chow. Rodent chow was custom-produced by Bio-Serve (Frenchtown, NJ). Lithium-containing chow was identical to the control chow with the exception of the added drug, and was produced at both a 'low' and 'normal' concentration (lithium carbonate; 1.2 and $2.4 \mathrm{~g} / \mathrm{kg}$ ). This administration paradigm has previously been used by our group in both rats and mice to achieve blood levels within the therapeutic range seen in humans (0.5-1.2 mM) (Gould et al, 2003, 2004a), and has also been shown to have behavioral effects (Einat et al, 2003). As with the clinical situation, mice were initially treated (for 1 week) at the lower dose, followed by 4 weeks of regular dose treatment. A subset of mice $(n=6)$ was utilized to determine serum and brain levels of lithium following the experiments. For serum lithium levels (mmol/ 1), serum was separated by centrifugation. Brain lithium levels (mmol/kg wet weight) were determined following polytron homogenization of the entire brain (Kinematica AG Model PCU 11; Littau, Switzerland) in 3 volumes of $0.5 \mathrm{~N}$ trichloroacetic acid, followed by centrifugation (Hamburger-Bar et al, 1986). Assays were performed with a digital flame photometer (Cole-Palmer Model 2655-00; Chicago, IL). The mean serum lithium level was $0.55 \pm 0.03 \mathrm{mM}$. The mean brain lithium level was $0.55 \pm 0.04 \mathrm{mmol} / \mathrm{kg}$ net weight.

\section{d-Amphetamine Hyperlocomotion and Sensitization}

Immediately after administration of $d$-amphetamine sulfate ( $2 \mathrm{mg} / \mathrm{kg}$ ) (Sigma, St Louis, MO, USA), mice were placed in the center of $35 \times 35 \times 35 \mathrm{~cm}$ Plexiglas arenas, and their behavior was recorded for $90 \mathrm{~min}$ by the Ethovision videotracking system. Data analysis was performed by Ethovision software, whereby distance moved within 5-min nested intervals was calculated and plotted. For the acute lithium experiments, mice were administered (i.p.) either lithium chloride (Sigma; St Louis, MO) dissolved in $0.9 \%$ saline, or saline alone. Fifteen minutes later, mice received (i.p.) $d$-amphetamine (Sigma; St Louis, MO) dissolved in saline. For the chronic lithium experiments, an identical treatment paradigm to that utilized in the FST was followed. Mice were placed in the Plexiglas arenas immediately following administration of $d$-amphetamine. In the sensitization experiment, mice received this same regimen once daily for 5 days. Locomotor activity was measured in the same arenas each of the 5 days, immediately following $d$-amphetamine administration.

\section{Stereotyped Behavior}

Wild-type mice were initially tested with various doses of $d$ amphetamine $(3.5-16 \mathrm{mg} / \mathrm{kg})$ to determine the appropriate dose for subsequent experiments. $12 \mathrm{mg} / \mathrm{kg}$ was the lowest dose that resulted in limited hyperlocomotion, while maximizing complex stereotyped behavior. Lithium chloride $(100 \mathrm{mg} / \mathrm{kg})$ or saline was administered i.p., and mice were returned to their home cages. Fifteen minutes later, $d$-amphetamine $(12 \mathrm{mg} / \mathrm{kg})$ was administered i.p., followed immediately by placement in center of clear $35 \times 35 \times 35 \mathrm{~cm}$ arenas in a sound-attenuated room with dim light $(\sim 35$ lux). Stereotypy began approximately $20 \mathrm{~min}$ after $d$ amphetamine administration, invariably beginning with stereotyped sniffing, and progressing rapidly into stereotyped biting and licking. After $30 \mathrm{~min}$, scoring began. A rater blind to treatment or genotype scored each mouse, using observational time sampling in a method modified from Kelley (2005). One point was assigned for each behavior observed during a time bin. For intensity scoring, one point was assigned for each additional $3 \mathrm{~s}$ that a behavior was observed in a time bin. Based on pilot experiments, behavioral categories were defined as follows: rear/climb, rearing up on hind paws, and/or attempting to climb up cage walls; sniff, continuous sniffing of air or arena; head bob, rapid up-and-down movement of head; bite/lick, biting or licking any part of the arena; and taffy pull, repetitive movement of front paws up to mouth/jaw, and back down to the chest while standing on the hind paws. Animals were scored for $60 \mathrm{~s}$ every $4 \mathrm{~min}$ for $1 \mathrm{~h}$.

\section{Determination of $\boldsymbol{\beta}$-Catenin Transgene Protein Levels}

Western blots were performed essentially as described (Gould et al, 2004a). Following homogenization, protein concentrations were determined using the Bio-Rad protein assay kit (Bradford, 1976). The linearity of the protein concentration for immunoblotting was ascertained by resolution of selected concentrations of protein. The amount of protein loaded was $0.375 \mu \mathrm{g} / \mathrm{lane}$. Proteins resolved by SDS-PAGE on $10 \%$ gels were then electrophoretically transferred to nitrocellulose membranes. Nonspecific binding on the nitrocellulose was blocked with TBST with 5\% nonfat dry milk, and then incubated with primary antibodies. Mouse monoclonal antibodies were from Sigma (anti-FLAG Peroxidase Conjugate (M2); St Louis, MO), Abcam (anti-GAPDH (ab8245); Cambridge, $\mathrm{MA}$ ), and Chemicon International (anti-actin (MAB1501); Temulca, CA). After blotting with anti-mouse secondary antibody (Cell Signaling Technology (\#7076), Beverly, MA; not performed in the case of the anti-FLAG antibody because it was peroxidase-conjugated), the immunocomplex was detected with the ECL plus kit (Amersham 
Biosciences, Piscataway, NJ) and BioMax MR scientific imaging film (Kodak, New Haven, CT).

\section{Statistical Analysis}

Statistics were two-tailed $t$-test, repeated measure two-way ANOVA, or post hoc tests, as appropriate. $p<0.05$ was considered significant.

\section{RESULTS}

\section{Initial Characterization of $\boldsymbol{\beta}$-Catenin Transgenic Mice}

Previous characterization of this strain (Mut-2) with immunohistochemistry revealed increased nuclear $\beta$-catenin in neurons of the cerebellum, hippocampus and cortex, which was confirmed by Western blot findings of increased cytosolic and nuclear $\beta$-catenin levels (Kratz et al, 2002). However, this previous report did not assess temporal and tissue specificity of transgene expression, which are critical issues for behavioral experiments. Western blot revealed high expression of transgenic $\beta$-catenin in the cortex, moderate expression in the hippocampus and striatum, lower expression in the cerebellum, and no expression in other tissues of the body (Figure 1a). As expected with the PrP promoter, limited expression was observed early postnatally, and levels reached those of adults at about 11 days of age (Figure $1 \mathrm{~b}$ ). These levels were maintained until at least 12 weeks (Figure 1b). All experiments were performed with mice between 8 and 12 weeks of age. The lack of early expression explains the lack of gross brain changes as observed with early embryonic overexpression of $\beta$-catenin in the mouse brain (Chenn and Walsh, 2002).

The $\beta$-catenin transgenic mice showed no gross neurological deficits in tests for vision, hearing, strength, balance, reflexes, social interactions, and aggression. They also did not exhibit abnormal spontaneous behaviors such as
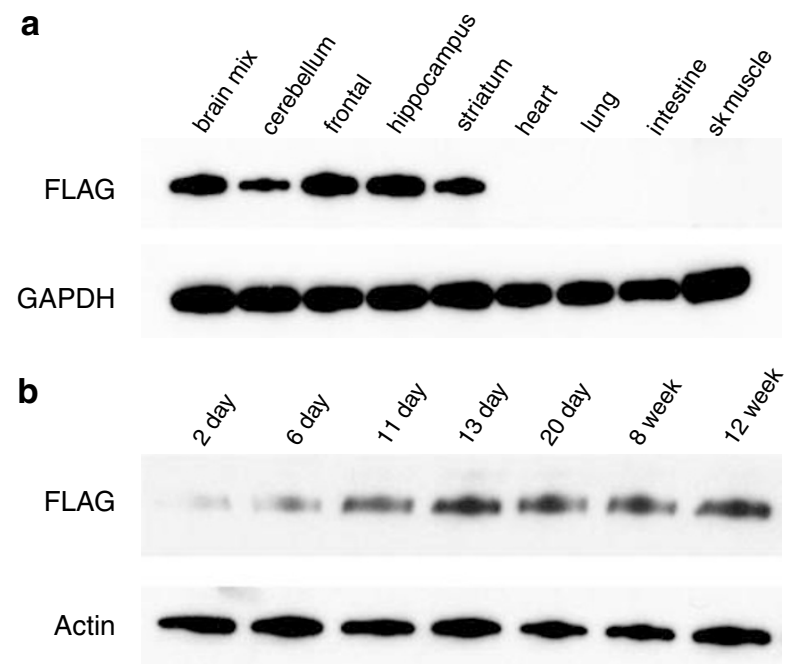

Figure I Transgene expression in $\beta$-catenin transgenic mice. Anti-FLAG antibodies were used to determine relative expression of the $\beta$-catenin transgene. (a) Western blot of various mouse tissues. (b) Western blot of transgene expression in the frontal cortex at various time points in days after birth. irregular running, excessive grooming, freezing, or altered body posture. Spontaneous locomotion over $45 \mathrm{~min}$ in a $120 \times 120 \mathrm{~cm}$ large open field was not significantly different between transgenic and wild-type mice (Figure 2a), nor was percent time spent in the center of this open field (a measure of anxiety; Supplementary Figure 7a, which is published as supplementary information on the Neuropsychopharmacology web site). In a second test for anxiety-like behavior, the black/white box, neither time in white nor number of entries was significantly different between genotypes (Figure 2b and Supplementary Figure $7 \mathrm{~b}$, published as supplementary information on the Neuropsychopharmacology web site). Motor learning assessed by the accelerating rotarod revealed a significant effect of trial number $(F(9,99)=20.13, p<0.0001)$, no significant effect of genotype, and no significant interaction between trial number and genotype (Figure 2c). Spatial memory was assessed in the Morris water maze. In the visible platform trial, two-way (genotype and trial number or day) repeated measures ANOVA revealed a significant effect of trial number $(F(7,91)=16.71, p<0.0001)$, no significant effects of genotype, and no significant interaction between trial number and genotype (Supplementary Figure 7c, published as supplementary information on the Neuropsychopharmacology web site). In the hidden platform trial, there was no significant effect of genotype, a significant effect of day $(\mathrm{F}(13,169)=4.64, p<0.0001)$, and no significant interaction between the two (Supplementary Figure 7d, published as supplementary information on the Neuropsychopharmaco$\log y$ web site). In the probe trial, two-way ANOVA revealed a significant effect of quadrant $(F(3,52)=12.94, p<0.001)$, no significant effect of genotype, and no significant interaction between the two. For both genotypes LSD post hoc test revealed a significant difference $(p<0.001)$ between the test quadrant and all other quadrants, but no other significant differences (Figure 4d).

\section{Forced Swim Test}

The FST is a validated mouse model of antidepressant efficacy (Porsolt et al, 1977), and has previously been shown to be sensitive to 10 days of lithium administration (O'Brien et al, 2004). A single injection of $100 \mathrm{mg} / \mathrm{kg}$ lithium chloride had no significant effects in the mouse FST in C57BL/6J mice (Figure 3a). We next treated mice with 4 weeks of lithium carbonate or control rodent chow. Similar to what has previously been observed following 10 days of lithium administration (O'Brien et al, 2004), 4 weeks of lithium administration decreased immobility time in the FST compared to control chow treated mice (Figure $3 \mathrm{~b}$; $(t(18)=2.96, p<0.01))$. These effects were maintained following 6 weeks of treatment (unpublished data). Interestingly, in our laboratory with this dose of lithium, we did not observe a difference in inactivity time following 10 days of lithium administration (unpublished data).

Similar to long-term lithium administration, the transgenic mice demonstrated robust antidepressant-like behavior, as shown by decreased immobility time in the FST (Figure 3c; $(t(21)=2.98, p<0.01))$. Specificity in this measure is supported by the lack of increased activity in the open-field activity (Figure 2a). Further, the decreased immobility in the FST was maintained following $30 \mathrm{~min}$ of 

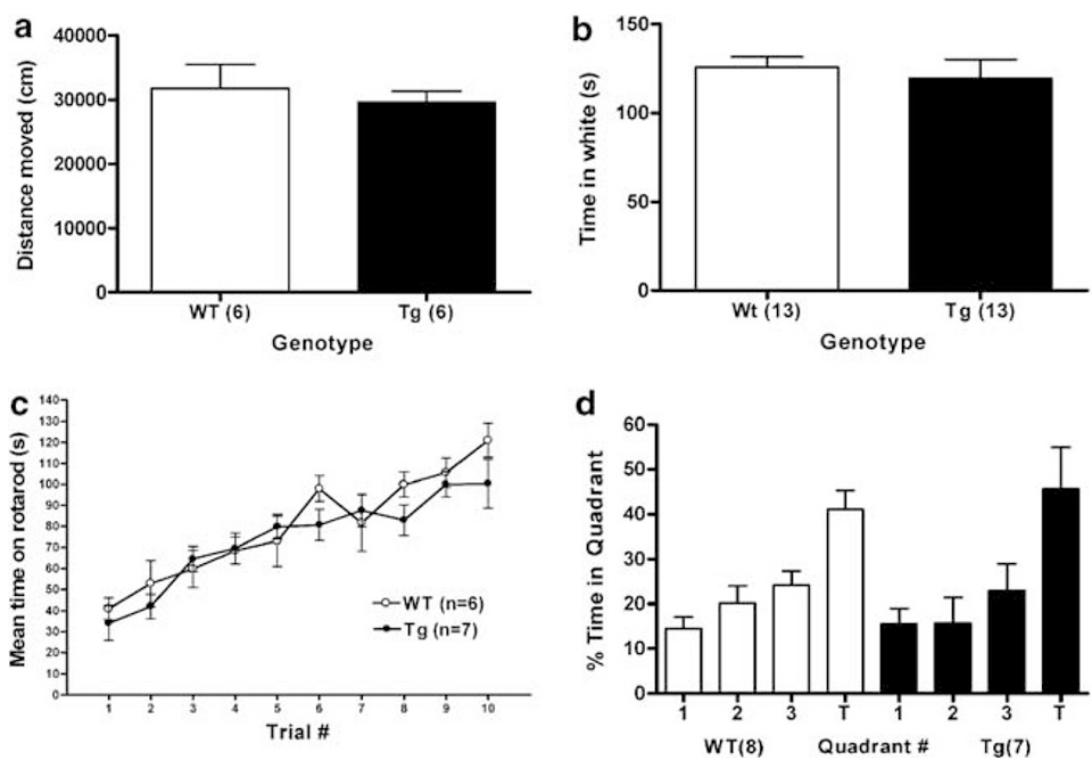

Figure 2 Initial behavioral phenotyping of $\beta$-catenin transgenic mice. No differences between transgenic and wild type animals were found in the following tests: (a) total distance moved in a large open field over 45 min. (b) Black-white box (time spent in white) over 5 min. (c) Repeated accelerating rotarod (four trials the first day, followed by three trials on days 2 and 3). (d) Morris water maze (removed platform trial shown). T: test quadrant.
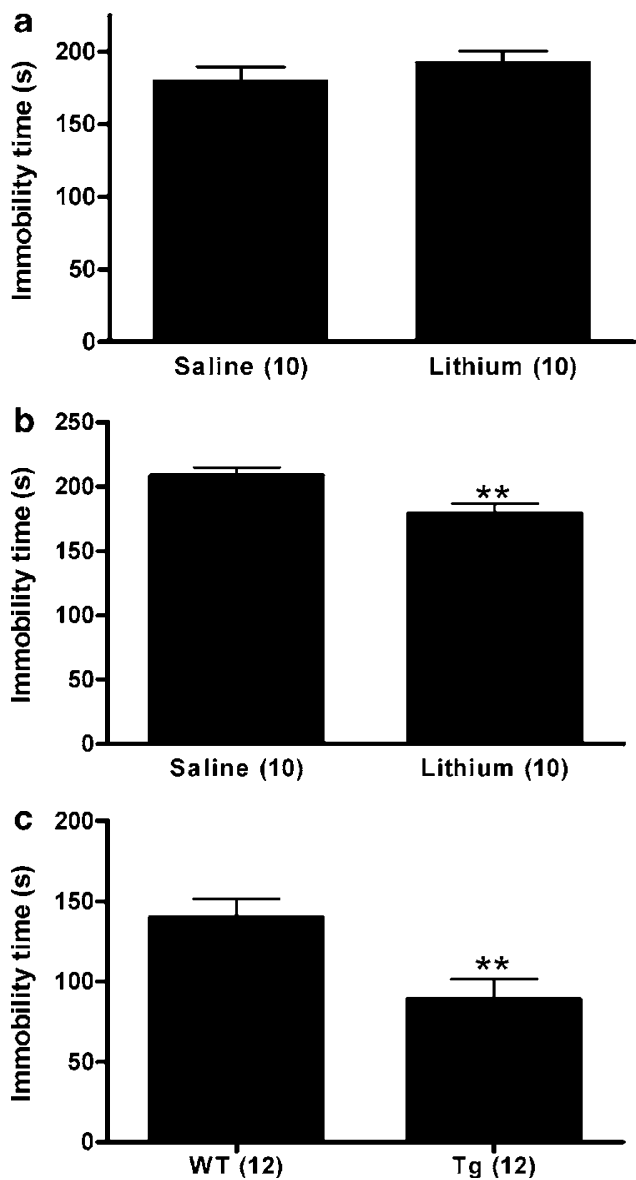

Figure 3 Forced swim test. (a) There was no significant effect of acute administration of $100 \mathrm{mg} / \mathrm{kg}$ lithium chloride in the FST in wild type (C57BL/6J) mice. (b) Four weeks of lithium administration to wild-type mice decreased inactivity time in the FST compared to control chow treated mice. (c) $\beta$-Catenin transgenic mice displayed decreased immobility time in the FST compared to their wild-type littermates. $* * 0<0.01$. restraint stress per day for 7 days (Supplementary Figure 8, published as supplementary information on the Neuropsychopharmacology web site; $(t(8)=2.56, p<0.05))$.

\section{d-Amphetamine Hyperlocomotion}

The effect of lithium to attenuate stimulant-induced hyperlocomotion in rodents has been widely replicated and is considered a model of the antimanic properties of the drug (Cox et al, 1971; Davies et al, 1974). A single injection of $100 \mathrm{mg} / \mathrm{kg}$ lithium chloride $15 \mathrm{~min}$ before $2 \mathrm{mg} / \mathrm{kg} d$ amphetamine attenuated hyperlocomotion in C57BL/6J mice over a period of $90 \mathrm{~min}$ (Figure 4a). Analysis of total distance moved revealed a significant effect of lithium chloride (Figure $4 \mathrm{~b} ;(t(21)=2.62, p<0.05)$ ). We have previously shown in our laboratory, consistent with the existing literature, that this dose of $\mathrm{LiCl}$, administered acutely, has no significant effect on baseline locomotion in C57BL/6J mice (Gould et al, in press). Further, these effects of lithium are also seen following 4 weeks of lithium carbonate administration (Figure 4c). Total distance moved was significantly different between groups (Figure 4d; $(t(22)=3.17, p<0.01)$. We have previously shown in our laboratory, consistent with the existing literature, that this dose of lithium carbonate, administered chronically, has no significant effect on baseline locomotion in C57BL/6J mice (Gould et al, in press).

Similar to both acute and long-term administration of lithium, transgenic mice were less responsive to the acute locomotor effects of 1 or $2 \mathrm{mg} / \mathrm{kg}$ i.p. $d$-amphetamine administration, as seen by locomotor activity curves (Figure $4 \mathrm{e}, \mathrm{f}$ and $\mathrm{g}$ ). There was also reduction in total distance traveled at both 1 and $2 \mathrm{mg} / \mathrm{kg} d$-amphetamine (Figure $4 \mathrm{~h}$; $1 \mathrm{mg} / \mathrm{kg} \quad(t(22)=2.11, \quad p<0.05), \quad 2 \mathrm{mg} / \mathrm{kg} \quad(t(21)=4.28$, $p<0.001)$. We did not do a two-way ANOVA comparison because the experiments were performed on separate days due to limited availability of transgenic mice. 

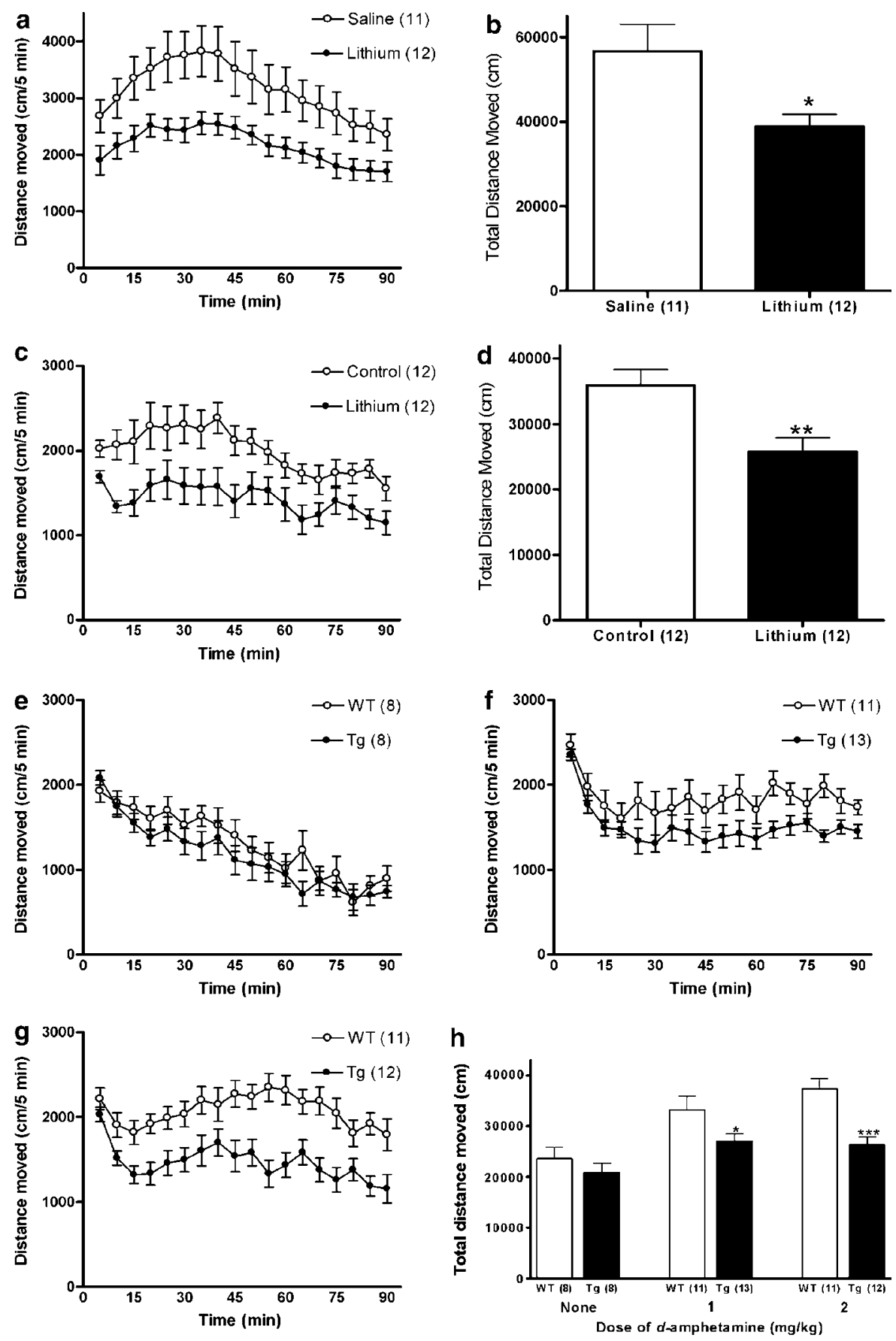

Figure $4 \mathrm{~d}$-Amphetamine hyperlocomotion. (a) $100 \mathrm{mg} / \mathrm{kg}$ lithium chloride or saline was administered I $5 \mathrm{~min}$ before $2 \mathrm{mg} / \mathrm{kg} \mathrm{d}$-amphetamine in wild-type (C57BL/6J) mice. Lithium chloride attenuated hyperlocomotion over a period of 90 min in $35 \times 35$ arenas. (b) Total distance moved after acute administration of lithium chloride and $2 \mathrm{mg} / \mathrm{kg} d$-amphetamine in wild type mice. (c) Lithium carbonate was administered for 4 weeks before $2 \mathrm{mg} / \mathrm{kg} d$ amphetamine in wild-type mice. (d) Total distance moved after chronic administration of lithium carbonate and $2 \mathrm{mg} / \mathrm{kg} d$-amphetamine in wild-type mice. (e) There was no significant difference in the baseline activity of $\beta$-catenin transgenic mice. However, they show less hyperlocomotion following administration of either $(\mathrm{f}) \mathrm{Img} / \mathrm{kg} d$-amphetamine or $(\mathrm{g}) 2 \mathrm{mg} / \mathrm{kg} d$-amphetamine. (h) Total distance moved at the three $d$-amphetamine concentrations in $\beta$-catenin transgenic mice. ${ }^{*} p<0.05$; $* *$ $p<0.01$; *** $p<0.001$.

\section{$d$-Amphetamine Sensitization}

We next studied the acute effects of lithium on $d$ amphetamine sensitization in C57BL/6J mice. Between days 1 and 5 an increased hyperlocomotor response was observed during the first $60 \mathrm{~min}$ of the test, indicating the development of sensitization (Figure $5 \mathrm{a}$ and $\mathrm{b}$ ). We therefore compared the first 60 min of activity by treatment and by day. Two-way repeated measure ANOVA revealed a significant effect of both lithium $(\mathrm{F}(1,56)=21.78, p<0.001)$, and day $(\mathrm{F}(4,56)=21.55, p<0.0001)$, with no significant interaction (Figure $5 \mathrm{c}$ ). The difference in total locomotion was maintained throughout the sensitization time-course (Figure 5c). Thus, lithium inhibited $d$-amphetamine-induced 
hyperlocomotion but did not prevent the development or expression of sensitization to the activity-inducing effect of $d$-amphetamine.

Similar to the effects of daily lithium administration, transgenic mice sensitized to $d$-amphetamine at a similar rate to their wild-type littermates, whereas the relative attenuation in activity in transgenic mice was maintained throughout each daily test in the 5-day trial (Figure 5d, $\mathrm{e}$ and $\mathrm{f}$ ). Two-way repeated measure ANOVA revealed a significant effect of both genotype $(\mathrm{F}(1,88)=14.83$, $p<0.001)$ and day $(\mathrm{F}(4,88)=28.09, p<0.0001)$, but no significant interaction. The difference in total locomotion was maintained throughout the sensitization time course.

\section{$d$-Amphetamine Stereotyped Behavior}

Administration of $12 \mathrm{mg} / \mathrm{kg} d$-amphetamine results in predictable stereotypy consisting of repetitive, locally oriented motor activities in C57BL/6J mice. $100 \mathrm{mg} / \mathrm{kg}$ lithium chloride or vehicle (saline) was administered $15 \mathrm{~min}$ before $d$-amphetamine. All animals treated with $d$-amphetamine, irrespective of genotype or treatment, exhibited biting or licking movements for virtually the entire hour. For other behaviors, more variation was observed (Figure $6 \mathrm{a}$ and b). Administration of $100 \mathrm{mg} / \mathrm{kg}$ lithium before $12 \mathrm{mg} / \mathrm{kg} d$-amphetamine had no significant effect on $d$-amphetamine-induced stereotyped behavior, measured as occurrence within each time bin (Figure 6a). Specifically, there was no significant effect of lithium on rearing, sniffing, taffy pull, head bob, or biting/licking. Further, the intensity of stereotypy was also not affected (Supplementary Figure 9a, published as supplementary information on the Neuropsychopharmacology web site).

Similar to the results seen with lithium in wild-type mice, $\beta$-catenin transgenic mice were not different from their wild-type littermates in the stereotyped response to $12 \mathrm{mg} /$ $\mathrm{kg} d$-amphetamine, measured as occurrence within each time bin (Figure 6b). Specifically, there was no significant


Figure 5 d-Amphetamine sensitization. Lithium was administered $15 \mathrm{~min}$ before $2 \mathrm{mg} / \mathrm{kg} \mathrm{d}$-amphetamine once a day for 5 days. (a, b) Locomotor activity curves for days I and 5 of sensitization in wild type (C57BL/6J) mice. (c) Distance moved for the first 60 min following d-amphetamine administration over 5 days in wild-type mice. (d, e) Locomotor activity curves for days I and 5 of sensitization in $\beta$-catenin transgenic mice and their wild-type littermates following $d$-amphetamine administration. (f) Distance moved for the first 60 min following $d$-amphetamine administration over 5 days in $\beta$-catenin mice and their wildtype littermates. $*_{p}<0.05$; ** $p<0.01$; **** $p<0.00$ I, LSD post hoc test comparison of daily results. 

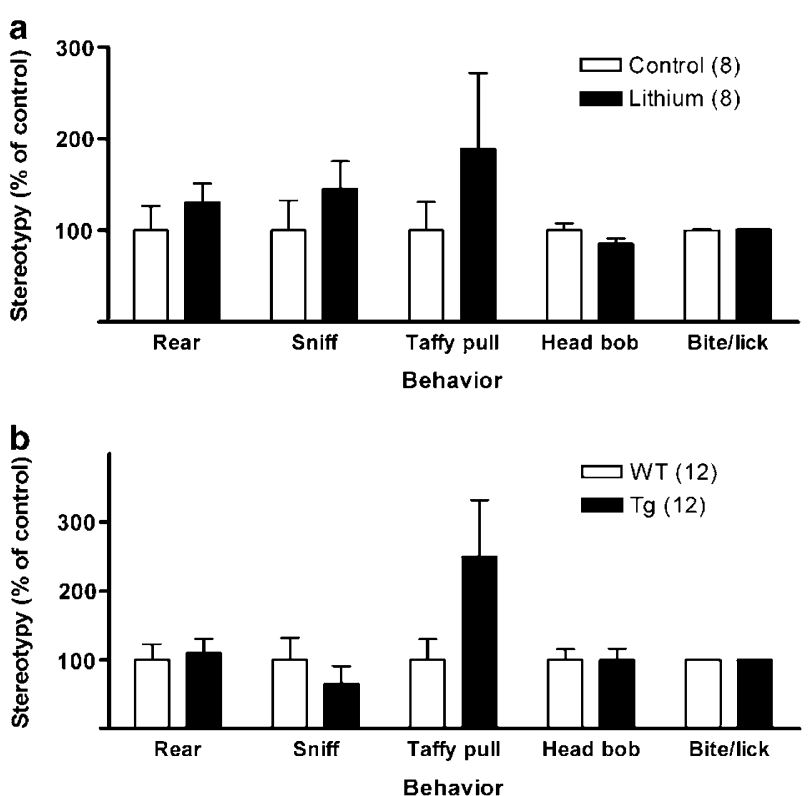

Figure 6 d-Amphetamine stereotypy. (a) $100 \mathrm{mg} / \mathrm{kg}$ lithium administration before $12 \mathrm{mg} / \mathrm{kg}$-amphetamine had no significant effect on $d$ amphetamine-induced stereotypy in wild-type (C57BL/6J) mice measured as an occurrence within each time bin. (b) The $\beta$-catenin transgene did not significantly affect stereotyped behavior induced by $12 \mathrm{mg} / \mathrm{kg}$ d-amphetamine.

effect of genotype on rearing, sniffing, taffy pull, head bob, or biting/licking. The intensity of stereotypy was also not affected (Supplementary Figure 9b, published as supplementary information on the Neuropsychopharmacology web site).

\section{DISCUSSION}

To determine the role of $\beta$-catenin in regulating the behavioral effects of lithium we utilized transgenic mice that overexpress a constitutively active form of $\beta$-catenin in the mouse brain (Kratz et al, 2002). We found that lithiumsensitive behaviors are phenocopied in these mice. In our paradigm, the FST is a behavioral model sensitive only to chronic administration of lithium, whereas acute lithium attenuates $d$-amphetamine hyperlocomotion without affecting development of either $d$-amphetamine sensitization or of $d$-amphetamine-induced stereotypy. We have shown that transgenic mice overexpressing $\beta$-catenin in the brain demonstrate behaviors similar to those observed following treatment of mice with lithium (Table 1). It is noteworthy that the lithium-sensitive behaviors observed are often considered prototypic models of both mania ( $d$-amphetamine-induced hyperlocomotion) and depression (FST), supporting the possibility that lithium's mood stabilizing effects are exerted, at least in part, through modulation of $\beta$-catenin. The lack of effect of lithium and the $\beta$-catenin transgene in $d$-amphetamine-induced locomotor sensitization and stereotypy may have relevance in discriminating the antimanic efficacy of lithium $v s$ the antimanic and antipsychotic efficacy of antipsychotic medications, as this latter class of drugs attenuates all three behaviors.
Table I Summary of Behavioral Results

\begin{tabular}{lll}
\hline & $\begin{array}{l}\text { Lithium } \\
\text { administration }\end{array}$ & $\begin{array}{l}\boldsymbol{\beta} \text {-catenin } \\
\text { tg mice }\end{array}$ \\
\hline d-Amphetamine hyperlocomotion & Decrease & Decrease \\
d-Amphetamine sensitization & No change & No change \\
d-Amphetamine stereotypy & No change & No change \\
Forced swim test (immobility time) & Decrease & Decrease \\
\hline
\end{tabular}

An understanding of the function of GSK-3 and of the Wnt pathway in the adult brain is constantly evolving. Beaulieu et al (2004) have recently reported that the effects of lithium on $d$-amphetamine-induced hyperlocomotion are mediated, in part, through a GSK-3-dependent mechanism. Specifically, they reported that $d$-amphetamine hyperlocomotion is also decreased in mice lacking one copy of GSK$3 \beta$. Furthermore, pharmacological inhibition of GSK-3 attenuates $d$-amphetamine hyperlocomotion in rats (Gould et al, 2004b). Similar to our findings (Figure 1b), O’Brien and colleagues (2004) reported that 10 days of lithium chloride administration results in an antidepressant-like effect (decreased immobility time) in the FST. Decreased immobility time in the FST has been observed following intraventricular injection of lithium to mice (Hagit EldarFinkelman, unpublished personal communication, February 2005), administration of alternate GSK-3 inhibitors in both mice (Kaidanovich-Beilin et al, 2004) and rats (Gould et al, $2004 \mathrm{~b}$ ), and in mice heterozygous for GSK-3 $\beta$ (O'Brien et al, 2004). Furthermore, administration of zinc, an inhibitor of GSK-3 $\beta$ (Ilouz et al, 2002), results in decreased immobility in the rat FST and reduced step down passive avoidance and hyperactivity in the olfactory bulbectomy model of depression in rats (Kroczka et al, 2000, 2001; Nowak et al, 2003). It has been previously reported that therapeutic levels of lithium increase $\beta$-catenin in the rodent brain (De Ferrari et al, 2003; Gould et al, 2004a, 2006; O'Brien et al, 2004). Further, therapeutic levels also increase Wnt-driven gene expression in mice (O'Brien et al, 2004). The findings of the previous studies that GSK-3 inhibitors decrease inactivity time in the FST have correlated these behaviors with an increase in $\beta$-catenin levels (Kaidanovich-Beilin et al, 2004; O'Brien et al, 2004). The present results suggest that $\beta$ catenin overexpression is sufficient to mediate these lithium-sensitive behaviors. These data implicate $\beta$-catenin as a mediator of the behavioral effects of lithium and of GSK-3 inhibition.

The effect of lithium to attenuate stimulant-induced hyperlocomotion in both mice and rats is very consistent in the literature (Cox et al, 1971; Davies et al, 1974). However, mixed results have been found regarding the effect of lithium on stimulant-induced stereotypy. Within rat studies, lithium has been found to decrease amphetamine-induced stereotypy (Flemenbaum, 1977), to have no effect on it (Fessler et al, 1982; Wielosz, 1976), or to potentiate it (Miyauchi et al, 1981), but both the dose and the isomer of amphetamine varied between the studies. There was no consistent association with strain, as all three possible outcomes were found even among Sprague-Dawley rats. Studies with mice were also inconclusive, with strain, 
dosage, and isomer differences obfuscating any firm conclusions. As in rats, lithium was found both to reduce (Frances et al, 1981) and to potentiate (Miyauchi et al, 1981; Ozawa and Miyauchi, 1977) stereotypy in mice.

Similarly, inconsistent results have been reported regarding the effects of lithium on stimulant sensitization. In rats, the inability of chronic lithium administration to inhibit sensitization to amphetamine or apomorphine has been reported (Rubin and Wooten, 1984). However, in this case, the measure of sensitization was amphetamine-induced stereotyped behavior. By contrast, lithium has prevented sensitization induced by multiple administrations of cocaine in rats as measured by hyperlocomotion (Post et al, 1984). Yang et al (2001) have tested the effect of lithium on sensitization to methylphenidate in rats, and have seen that it is capable of suppressing the development of sensitization early on, but was unable to prevent its expression after a later re-challenge. They also showed that lithium has no effect on sensitization to methylphenidate once it has developed. Namima et al (1999), using a considerably higher dose $(170 \mathrm{mg} / \mathrm{kg})$ of lithium chloride given to ddy mice, also administered five times but at intervals of 3 days, reported prolonged attenuation of methamphetamine hyperlocomotion by lithium administration. However, our data clearly show no effect of acute lithium to prevent $d$-amphetamine stereotypy or sensitization in $\mathrm{C} 57 \mathrm{BL} / 6 \mathrm{~J}$ mice at non-toxic doses of lithium.

A recent study suggests that a common functional GSK-3 $\beta$ promoter polymorphism, $(-50 \mathrm{~T} / \mathrm{C})$, is associated with response to lithium in a group of 88 bipolar disorder type I patients (Benedetti et al, 2005; Kwok et al, 2005). Future experiments may specifically observe the effect of this polymorphism in endophenotypic human clinical measurements of the lithium-sensitive behaviors we describe (Gottesman and Gould, 2003; Hasler et al, 2006). In addition to lithium's direct effects on GSK-3, indirect inhibition is caused by a diverse range of mood stabilizers and antidepressants, including valproate, electroconvulsive seizures (ECS; an animal model of electroconvulsive therapy), MAOIs, fluoxetine, imipramine, estrogen, clozapine, risperidone, and haloperidol (see Gould and Manji, 2005 for review of these data). Thus, GSK-3 may be a common pathway on which medications useful for the treatment of mood disorders converge, and for this reason it may be a target for novel medications.

Although $\beta$-catenin's actions in cell fate during development are established, its full functions in the adult mammalian nervous system are not entirely known. In the Wnt pathway, $\beta$-catenin functions as a transcription factor regulating gene expression. Recent work suggests that the Wnt signaling pathway provides neuroprotective effects from ischemia and NMDA toxicity (Cappuccio et al, 2005), and contributes to regulating neurogenesis (Lie et al, 2005; Madsen et al, 2003). Major pharmaceutical interest in the development of novel, potent inhibitors of GSK-3 currently exists. (see Cohen and Goedert, 2004 for review). Increasing preclinical evidence, such as that presented here, makes it likely that GSK-3 inhibitors will be utilized in bipolar disorder proof-of-concept trials. Further, our data, which implicate $\beta$-catenin as a downstream target of lithium (and GSK-3) relevant to the behavioral effects, suggest that approaches to manipulate this target may be of fundamental interest in the development of lithium-mimetic compounds.

\section{ACKNOWLEDGEMENTS}

We thank Dr Charles Eberhart (Johns Hopkins University) for the $\beta$-catenin transgenic mice, Dr Francois Vautier for assistance with the Morris water maze protocol, and David A Luckenbaugh, NIMH Mood and Anxiety Disorders Program Biostatistician, for statistical assistance. This research was supported by the Intramural Research Program of the National Institute of Mental Heath, the Foundation for the National Institutes of Health (Neuroscience Research Fellowship (TDG)), the National Association for Research on Schizophrenia and Depression (Young Investigator Award to TDG and $\mathrm{HE}$ ), and the Stanley Research Foundation (HKM). The authors have no conflicts of interest, financial or otherwise.

\section{REFERENCES}

Aberle H, Bauer A, Stappert J, Kispert A, Kemler R (1997). Betacatenin is a target for the ubiquitin-proteasome pathway. $E M B O$ J 16: 3797-3804.

Beaulieu JM, Sotnikova TD, Yao WD, Kockeritz L, Woodgett JR, Gainetdinov RR et al (2004). Lithium antagonizes dopaminedependent behaviors mediated by an AKT/glycogen synthase kinase 3 signaling cascade. Proc Natl Acad Sci USA 101: 5099-5104.

Behrens J, Jerchow BA, Wurtele M, Grimm J, Asbrand C, Wirtz R et al (1998). Functional interaction of an axin homolog, conductin, with beta-catenin, APC, and GSK3beta. Science 280: 596-599.

Benedetti F, Serretti A, Pontiggia A, Bernasconi A, Lorenzi C, Colombo $\mathrm{C}$ et al (2005). Long-term response to lithium salts in bipolar illness is influenced by the glycogen synthase kinase 3beta-50 T/C SNP. Neurosci Lett 376: 51-55.

Borchelt DR, Davis J, Fischer M, Lee MK, Slunt HH, Ratovitsky T et al (1996). A vector for expressing foreign genes in the brains and hearts of transgenic mice. Genet Anal 13: 159-163.

Bradford MM. (1976). A rapid and sensitive method for the quantitation of microgram quantities of protein utilizing the principle of protein-dye binding. Anal Biochem 72: 248-254.

Cappuccio I, Calderone A, Busceti CL, Biagioni F, Pontarelli F, Bruno $\mathrm{V}$ et al (2005). Induction of Dickkopf-1, a negative modulator of the Wnt pathway, is required for the development of ischemic neuronal death. J Neurosci 25: 2647-2657.

Chenn A, Walsh CA (2002). Regulation of cerebral cortical size by control of cell cycle exit in neural precursors. Science 297: 365-369.

Cohen P, Goedert M (2004). GSK3 inhibitors: development and therapeutic potential. Nat Rev Drug Discov 3: 479-487.

Cox C, Harrison-Read PE, Steinberg H, Tomkiewicz M (1971). Lithium attenuates drug-induced hyperactivity in rats. Nature 232: 336-338.

Crawley JN (2000). What's Wrong with My Mouse?: Behavioral Phenotyping of Transgenic and Knockout Mice. Wiley-Liss: New York. xiii, 329pp.

Davies C, Sanger DJ, Steinberg H, Tomkiewicz M, U'Prichard DC (1974). Lithium and alpha-methyl-p-tyrosine prevent 'manic' activity in rodents. Psychopharmacologia 36: 263-274. 
De Ferrari GV, Chacon MA, Barria MI, Garrido JL, Godoy JA, Olivares $G$ et al (2003). Activation of Wnt signaling rescues neurodegeneration and behavioral impairments induced by beta-amyloid fibrils. Mol Psychiatry 8: 195-208.

Einat H, Yuan P, Gould TD, Li J, Du J, Zhang L et al (2003). The role of the extracellular signal-regulated kinase signaling pathway in mood modulation. J Neurosci 23: 7311-7316.

Fessler RG, Sturgeon RD, London SF, Meltzer HY (1982). Effects of lithium on behaviour induced by phencyclidine and amphetamine in rats. Psychopharmacology (Berlin) 78: 373-376.

Flemenbaum A (1977). Lithium inhibition of norepinephrine and dopamine receptors. Biol Psychiatry 12: 563-572.

Frances H, Marion MH, Simon P (1981). Antidepressant action of lithium: proposed mechanism based upon behavioral analysis in the mouse. Prog Neuropsychopharmacol 5: 357-361.

Furlong MT, Morin PJ (2000). Rare activation of the TCF/betacatenin pathway in ovarian cancer. Gynecol Oncol 77: 97-104.

Gottesman II, Gould TD (2003). The endophenotype concept in psychiatry: etymology and strategic intentions. Am J Psychiatry 160: 636-645.

Gould TD, Chen G, Manji HK (2004a). In vivo evidence in the brain for lithium inhibition of glycogen synthase kinase-3. Neuropsychopharmacology 29: 32-38.

Gould TD, Einat H, Bhat R, Manji HK (2004b). AR-A014418, a selective GSK-3 inhibitor, produces antidepressant-like effects in the forced swim test. Int J Neuropsychopharmacol 7: 387-390.

Gould TD, Gray NA, Manji HK (2003). Effects of a glycogen synthase kinase-3 inhibitor, lithium, in adenomatous polyposis coli mutant mice. Pharmacol Res 48: 49-53.

Gould TD, Manji HK (2005). Glycogen synthase kinase-3: a putative molecular target for lithium mimetic drugs. Neuropsychopharmacology 30: 1223-1237.

Gould TD, O'Donnell KC, Picchini AM, Manji HK Strain difference in lithium attenuation of d-amphetamine hyperlocomotion: a mouse model for the genetics of lithium response. Neuropsychopharmacology [E-pub ahead of print].

Gould TD, Picchini AM, Einat H, Manji HK (2006). Targeting glycogen synthase kinase-3 in the CNS: implications for the development of new treatments for mood disorders. Curr Drug Targets 7: 1399-1409.

Gould TD, Quiroz JA, Singh J, Zarate CA, Manji HK (2004c). Emerging experimental therapeutics for bipolar disorder: insights from the molecular and cellular actions of current mood stabilizers. Mol Psychiatry 9: 734-755.

Hamburger-Bar R, Robert M, Newman M, Belmaker RH (1986). Interstrain correlation between behavioural effects of lithium and effects on cortical cyclic AMP. Pharmacol Biochem Behav 24: 9-13.

Hasler G, Drevets WC, Gould TD, Gottesman II, Manji HK (2006). Toward constructing an endophenotype strategy for bipolar disorders. Biol Psychiatry 60: 93-105.

Ilouz R, Kaidanovich O, Gurwitz D, Eldar-Finkelman H (2002). Inhibition of glycogen synthase kinase-3beta by bivalent zinc ions: insight into the insulin-mimetic action of zinc. Biochem Biophys Res Commun 295: 102-106.

Institute of Laboratory Animal Resources (US) (1996). Guide for the Care and Use of Laboratory Animals. National Academy Press: Washington, DC. xii, 125pp.

Kaidanovich-Beilin O, Milman A, Weizman A, Pick CG, Eldar-Finkelman H (2004). Rapid antidepressive-like activity of specific glycogen synthase kinase-3 inhibitor and its effect on beta-catenin in mouse hippocampus. Biol Psychiatry 55: 781-784.

Kelley AE (2005). Measurement of rodent stereotyped behavior. In: Crawley JN, Gerfen CR, Rogawski MA, Sibley DR, Skolnick P,
Wray S (eds). Current Protocols in Neuroscience. John Wiley \& Sons: New York, NY. pp 8.8.1-8.8.13.

Klein PS, Melton DA (1996). A molecular mechanism for the effect of lithium on development. Proc Natl Acad Sci USA 93: 8455-8459.

Kratz JE, Stearns D, Huso DL, Slunt HH, Price DL, Borchelt DR et al (2002). Expression of stabilized beta-catenin in differentiated neurons of transgenic mice does not result in tumor formation. BMC Cancer 2: 33.

Kroczka B, Branski P, Palucha A, Pilc A, Nowak G (2001). Antidepressant-like properties of zinc in rodent forced swim test. Brain Res Bull 55: 297-300.

Kroczka B, Zieba A, Dudek D, Pilc A, Nowak G (2000). Zinc exhibits an antidepressant-like effect in the forced swimming test in mice. Pol J Pharmacol 52: 403-406.

Kwok JB, Hallupp M, Loy CT, Chan DK, Woo J, Mellick GD et al (2005). GSK3B polymorphisms alter transcription and splicing in Parkinson's disease. Ann Neurol 58: 829-839.

Lie DC, Colamarino SA, Song HJ, Desire L, Mira H, Consiglio A et al (2005). Wnt signalling regulates adult hippocampal neurogenesis. Nature 437: 1370-1375.

Madsen TM, Newton SS, Eaton ME, Russell DS, Duman RS (2003). Chronic electroconvulsive seizure up-regulates beta-catenin expression in rat hippocampus: role in adult neurogenesis. Biol Psychiatry 54: 1006-1014.

Miyauchi T, Kikuchi K, Satoh S (1981). Further studies on the potentiating effect of lithium chloride on methamphetamineinduced stereotypy in mice. Jpn J Pharmacol 31: 61-68.

Naccarato WF, Ray RE, Wells WW (1974). Biosynthesis of myoinositol in rat mammary gland. Isolation and properties of the enzymes. Arch Biochem Biophys 164: 194-201.

Namima M, Sugihara K, Watanabe Y, Sasa H, Umekage T, Okamoto K (1999). Quantitative analysis of the effects of lithium on the reverse tolerance and the c-Fos expression induced by methamphetamine in mice. Brain Res Brain Res Protoc 4: $11-18$.

Nowak G, Szewczyk B, Wieronska JM, Branski P, Palucha A, Pilc A et al (2003). Antidepressant-like effects of acute and chronic treatment with zinc in forced swim test and olfactory bulbectomy model in rats. Brain Res Bull 61: 159-164.

O'Brien WT, Harper AD, Jove F, Woodgett JR, Maretto S, Piccolo S et al (2004). Glycogen synthase kinase-3beta haploinsufficiency mimics the behavioral and molecular effects of lithium. J Neurosci 24: 6791-6798.

Orford K, Crockett C, Jensen JP, Weissman AM, Byers SW (1997). Serine phosphorylation-regulated ubiquitination and degradation of beta-catenin. J Biol Chem 272: 24735-24738.

Ozawa H, Miyauchi T (1977). Potentiating effect of lithium chloride on methamphetamine-induced stereotypy in mice. Eur J Pharmacol 41: 213-216.

Peifer M, Pai LM, Casey M (1994). Phosphorylation of the Drosophila adherens junction protein Armadillo: roles for wingless signal and zeste-white 3 kinase. Dev Biol 166: 543-556.

Porsolt RD, Le Pichon M, Jalfre M (1977). Depression: a new animal model sensitive to antidepressant treatments. Nature 266 730-732.

Post RM, Weiss SR, Pert A (1984). Differential effects of carbamazepine and lithium on sensitization and kindling. Prog Neuropsychopharmacol Biol Psychiatry 8: 425-434.

Ray Jr WJ, Szymanki ES, Ng L (1978). The binding of lithium and of anionic metabolites to phosphoglucomutase. Biochim Biophys Acta 522: 434-442.

Rubin EH, Wooten GF (1984). The behavioral and biochemical effects of lithium on dopaminergic agonist-induced supersensitivity. Psychopharmacology (Berlin) 84: 217-220.

Stambolic V, Ruel L, Woodgett JR (1996). Lithium inhibits glycogen synthase kinase- 3 activity and mimics wingless signalling in intact cells. Curr Biol 6: 1664-1668. 
Wielosz M (1976). The effect of lithium chloride on the activity of some psychotropic drugs. Pol J Pharmacol Pharm 28: 189-198.

Yang P, Singhal N, Modi G, Swann A, Dafny N (2001). Effects of lithium chloride on induction and expression of methylphenidate sensitization. Eur J Pharmacol 426: 65-72.

York JD, Ponder JW, Majerus PW (1995). Definition of a metaldependent/Li(+)-inhibited phosphomonoesterase protein family based upon a conserved three-dimensional core structure. Proc Natl Acad Sci USA 92: 5149-5153.

Yost C, Torres M, Miller JR, Huang E, Kimelman D, Moon RT (1996). The axis-inducing activity, stability, and subcellular distribution of beta-catenin is regulated in Xenopus embryos by glycogen synthase kinase 3. Genes Dev 10: 1443-1454.

Supplementary Information accompanies the paper on the Neuropsychopharmacology website (http://www.nature.com/npp) 